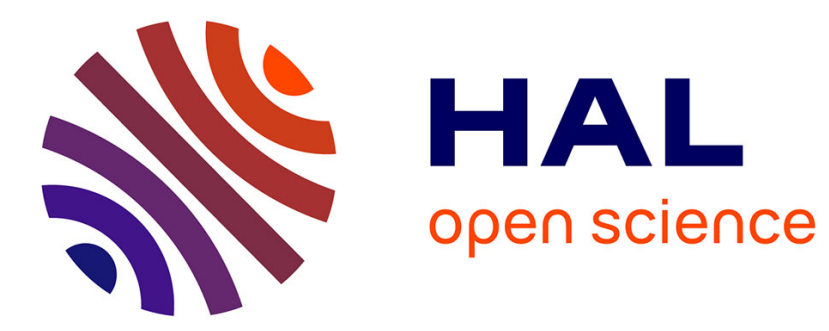

\title{
An insight of combustibility induced safety issues pertaining to ionic liquids
}

Alpha-Oumar Diallo, Benjamin Truchot, Guy Marlair, Christophe Len

\section{To cite this version:}

Alpha-Oumar Diallo, Benjamin Truchot, Guy Marlair, Christophe Len. An insight of combustibility induced safety issues pertaining to ionic liquids. 7. International seminar on fire and explosion hazards (ISFEH 7), May 2013, Providence, United States. pp.NC, 10.3850/978-981-07-5936-0_03-06 . ineris00976246v2

HAL Id: ineris-00976246

https: / hal-ineris.archives-ouvertes.fr/ineris-00976246v2

Submitted on 10 Apr 2014

HAL is a multi-disciplinary open access archive for the deposit and dissemination of scientific research documents, whether they are published or not. The documents may come from teaching and research institutions in France or abroad, or from public or private research centers.
L'archive ouverte pluridisciplinaire HAL, est destinée au dépôt et à la diffusion de documents scientifiques de niveau recherche, publiés ou non, émanant des établissements d'enseignement et de recherche français ou étrangers, des laboratoires publics ou privés. 


\title{
An Insight of Combustibility Induced Safety Issues Pertaining to lonic Liquids
}

\author{
Diallo, A.o. ${ }^{1}$, Truchot, B. ${ }^{1}$, Marlair, G. ${ }^{1 *}$, and Len, C. ${ }^{2}$ \\ ${ }^{1}$ Institut National de l'Environnement Industriel et des Risques (INERIS), \\ Direction des Risques Accidentels, Parc Technologique Alata, Verneuil en Halatte, France. \\ ${ }^{2} U T C-E S C O M, E A ~ 4297$, Transformations Intégrées de la Matière Renouvelable, \\ Centre de Recherches de Royallieu, Compiègne Cedex, France. \\ *Corresponding author email: guy.marlair@ineris.fr
}

\begin{abstract}
This study is a consolidated overview on explosion and fire safety issues pertaining to ionic liquids. Indeed safety performance of ionic liquids relating to physico-chemical hazards is very rarely investigated as it is often perceived as a non-existing issue due to the lack of traditional flashpoint for these liquids. It focuses on the experimental evaluation of the fire hazard of imidazolium, phosphonium and pyrrolidinium-based ionic liquids by use of the Fire Propagation Apparatus. It provides experimental data that can quantify the flammability of ionic liquids in all its aspects (ease of ignition, mass burning rate, heat release rate, fire-induced toxicity data...). A case study featuring a major failure in a process unit leading to a given fire scenario is also illustrated. This case study is examined in terms of fire induced toxicity by use of CFD modeling of fire product releases dispersion and using the concept of fractional effective concentration.
\end{abstract}

KEYWORDS: Explosion hazard, flammability, ionic liquids, toxicity issues.

\section{INTRODUCTION}

Ionic liquids (ILs) are in the focus of recent research and more and more considered for use in emerging industrial applications. Because of their unique physical properties (e.g., high thermal stability, large liquid range, negligible vapor pressure), these chemicals are used in many domains, such as energy conversion and storage [1], biomass pre-treatment [2], metal processing [3], engineering fluids [4], and polymer additives [5]. They are made by association of large organic cations (e.g. imidazolium, phosphonium, pyrrolidinium, pyridinium, ammonium, guanidinium...) with a variety of counter-anions (halogens, $\mathrm{BF}_{4}, \mathrm{PF}_{6}$ and many others) that are liquids under $100^{\circ} \mathrm{C}$. Many of them are already liquid below room temperature (and in such a case designated as Room Temperature ILs (RTILs)).

The growing interest in ILs in the early 2000s was partly due to the generic assumption that these materials were implicitly highly stable, non-flammable, or safe to use in any process [6-8]. Owing to infinite combinations of cations and anions, potentially billions of such materials are in existence. Surprisingly, some of them are considered as promising energetic materials for application as propellants [9], showing that combustibility in such case is perceived as a technical advantage. Even if there is practically no study about toxicity of ILs to humans, many are moderately or very toxic to aquatic organisms and non-biodegradable. The general assumption that prevailed for a long time that ILs were green chemicals per se has to be revised, which is no longer questionable, due to their toxic potency. In addition, recent findings have shown that safety assessments of ILs must not only encompass toxicity and ecotoxicity issues, but also the full range of physico-chemical hazards including combustibility. Therefore, sustainable use of such materials must be studied on a case by case basis, considering adequate analysis of physicochemical and health safety, disposal and potential environmental impacts of them. 
As a continuation of our previous research on the actual fire hazards of ILs, the paper gives a short literature review on flammability and explosivity hazards of ILs. It mostly focuses on the experimental evaluation of the fire hazard of imidazolium, phosphonium and pyrrolidiniumbased ionic liquids, including a case study featuring a major failure in a process unit leading to a given fire scenario (pool burning). This case study is examined in terms of fire induced toxicity by use of CFD modeling of fire product releases dispersion and using the concept of fractional effective concentration (FEC), as defined in ISO 13571 [10].

\section{REVIEW ON FLAMMABILITY AND EXPLOSIVITY HAZARDS OF IONIC LIQUIDS}

ILs have long been labeled and described as "not flammable" due to their low vapor pressure and measured flash point. Although so far no industrial accident involving an $\mathrm{IL}$ has been listed, two recently informally reported laboratory incidents during and just after synthesis of ILs containing nitrate anion (e.g. ethyl-ammonium nitrate) have taken place in the EU. Both these incidents have resulted in explosion events that are confirming that the explosion hazard of ILs must not be neglected in some cases.

More frequently, self-sustained or piloted combustion of some ILs have been shown as a potential incidental scenario in some experiments. In most cases, rapid exothermic decomposition occurs when ILs with high nitrogen content are taken to high temperature and the subsequent decomposition products are sensitive to ignition and combustion. The combustion may tend to be explosive even under vacuum as shown by Smiglak et al. [11] for imidazoliumbased ILs or hydrazinium-based ILs tested in their work.

In addition, burning tests performed on 4-amino-1-methyl-1,2,4-triazolium nitrate by Schaller [12] have led to a flame temperature of $2200 \mathrm{~K}$. In some cases ILs are even combustible by design where intended for use as propellants as alternatives to hydrazine [13]. Ultimately, once the various molecular bonds reach their thermal decomposition temperature in these carbonbased ILs, smaller and more flammable molecules could be released leading to combustion similarly to polymer combustion.

Flammability issues may also arise from specific behavior of hypergolic ILs. When in contact with the dinitrogen tetroxide $\left(\mathrm{N}_{2} \mathrm{O} 4\right)$ or white fuming nitric acid (WFNA) those hypergolic materials can spontaneously ignite due to the highly exothermic reaction that takes place. It was shown that ILs with the dicyanamide or nitrocyanamide anion in particular are hypergolic [1416]. Also, 2,2-dimethyltriazanium nitrate and 2,2-dimethyltriazanium chloride are hypergolic prone materials [17], suggesting that also the nature of the cation of the $\mathrm{IL}$ can modify hypergolic properties.

These examples show again that the traditional flashpoint type tests are certainly not adequate in most cases to properly characterize the fire hazard, as reported by Liaw et al. [18]. This is related to our findings that ILs do not behave as traditional flammable liquids where the fire results from the combustion of the vapor phase of the concerned chemical. Our analysis [19] confirms therefore that the flammability hazard of ILs must be revisited, as those liquids show a burning behavior closely comparable to that of poly mers rather than that of flammable solvents.

\section{BRIEF DESCRIPTION OF THE MAIN EXPERIMENTAL RESULTS}

\section{The Fire Propagation Apparatus (FPA)}

The fire behavior of ILs was determined using the FPA (standard ISO 12136), also called Tewarson calorimeter. This bench-scale fire calorimeter implemented at INERIS some 15 years ago has been described in detail in many studies [20-22]. It belongs to the family of fire 
calorimeters that are bench-scale multipurpose testing apparatuses focusing on the characterization of burning behavior of materials and products in fire conditions. Figure 1 represents a schematic drawing of the FPA installed in the INERIS fire lab. Testing capability of the equipment encompasses ignitability, fire propagation potential, thermal and chemical characteristics in fire conditions. Repeatability and reproducibility of data count among the major advantages of the equipment together with its capacity for revealing atypical fire phenomena, like-liquid phase decomposition process of organophosphorous pesticides. In particular, parametric tests on product samples of about 25-50 g under controlled air intake allow for characterizing the fire behavior of the studied material or product (liquid, solid, gas) on the full spectrum of fire conditions (fuel rich or fuel lean). Scientific-sound diagnosis of the fire behavior of materials is achieved thanks to the access to key measures such as mass loss, Heat Release Rate (HRR) by application of fire calorimetry laws based on the assessment of oxygen consumption (OC) and carbon dioxide generation (CDG), measurements of fire effluent concentrations and related emission yields allowing for an evaluation of pollutants and fire toxicity issues.

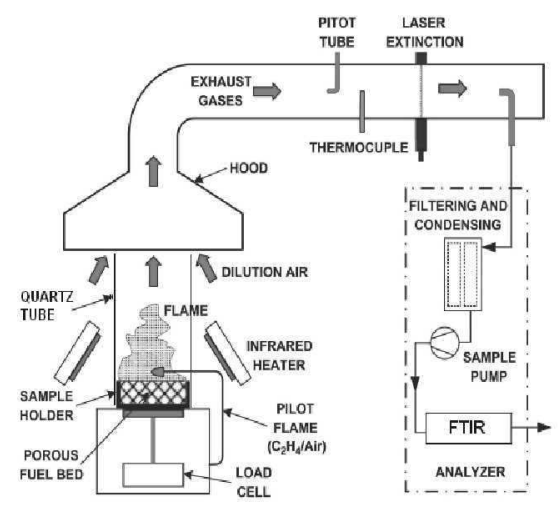

Figure 1. Schematic view of the FPA.

\section{Fire Propagation Apparatus (FPA) Tests}

A sample of tributyl(methyl)phosphonium methylsulfate $\left(\left[\mathrm{P}_{4,4,4,1}\right]\left[\mathrm{MeOSO}_{3}\right]\right)$ was kindly supplied by the Cytec Company. According to the MSDS supplied by Cytec the purity level was $96.7 \%$ based on phosphorus ${ }^{31} \mathrm{P}$ NMR. Samples of Lithium bis(trifluoromethanesulfonyl)imide (LiTFSI), 1-butyl-1-methylpyrrolidinium bis(trifluoromethanesulfonyl)imide) ([PYR 14$][T F S I])$ and 1-butyl-3-methylimidazolium bis(trifluoromethanesulfonyl)imide ([BMIM][TFSI]) with purity levels of $99.9 \%, 99 \%$ and $99 \%$, respectively, were purchased from Solvionic. The LiTFSI was added to [BMIM][TFSI] to obtain a solution of 1M of LiTFSI in [BMIM][TFSI], this mixture is thought to be a good candidate as electrolyte component in lithium-ion rechargeable batteries.

ILs samples and the mixture were tested in the FPA without any further purification step under an external heat flux of $50 \mathrm{~kW} / \mathrm{m}^{2}$ until ignition was observed, in order to achieve ignition in reasonably short time considering observed good to fairly good resistance to ignition in most cases. Sustained combustion following ignition requires conditions that may highly differ according to studied ILs. In this study, the external heat flux maintained after ignition was $25 \mathrm{~kW} / \mathrm{m}^{2}$ in all cases. Smoke analysis was performed by use of an online Fourier Transform Infrared (FTIR) spectrometer calibrated over 20 gases for derivation of $\mathrm{CO}_{2}, \mathrm{CO}, \mathrm{SO}_{2}, \mathrm{NOx}$, $\mathrm{HCN}, \mathrm{HCl}$, and $\mathrm{HF}$ concentrations and mass release rate versus time. An overview of the results obtained from the combustion of ILs in the FPA is summarized in Table 1. In addition, the theoretical energy of combustion of those materials measured in an oxygen bomb calorimeter 
following ASTM D240 protocol were given. The data and the observations made during the tests confirm generally good resistance to ignition of the ILs, based on the ignition time required under the applied external heat flux in the initial phase of the tests $\left(50 \mathrm{~kW} / \mathrm{m}^{2}\right)$. However, once ignition was obtained, sustained and flaming combustion phases were observed and characterized, confirming the real combustibility of all the ILs tested. Products emission factors reveal that high conversion rates of hetero-atoms in parent toxic effluents are obtained in several cases. The combustion of ILs having fluorine elements leads to the formation of HF. Whereas the presence of fluorine in organo-halogenated materials generally contributes to good flame retardancy of such materials, its conversion into HF in fire environments triggers unique hazards to exposed people and fire fighters and even equipment. This fact may justify careful evaluations before the practical use of ILs in laboratory and industrial settings.

Table 1. Burning behavior of ILs in the FPA

\begin{tabular}{|c|c|c|c|}
\hline Ionic Liquid & {$\left[\mathrm{P}_{4,4,4,1}\right]\left[\mathrm{MeOSO}_{3}\right]$} & $\begin{array}{c}\text { [BMIM][TFSI] } \\
\text { 1M LiTFSI }\end{array}$ & {$\left[\mathrm{PYR}_{14}\right][\mathrm{TFSI}]$} \\
\hline Initial mass [g] & 32.5 & 61.9 & 51.3 \\
\hline Char residue [\%] & 6.5 & 14.9 & 5.7 \\
\hline Time to ignition [s] & 200 & 294 & 280 \\
\hline $\begin{array}{l}\text { Average mass lost rate } \\
{\left[\mathrm{g} / \mathrm{m}^{2} / \mathrm{s}\right]}\end{array}$ & 33 & 46.6 & 24 \\
\hline \multicolumn{4}{|c|}{ Heat of combustion $[\mathrm{MJ} / \mathrm{kg}]$} \\
\hline Theoretical heat of combustion & 28.3 & 10.8 & 14.8 \\
\hline OC method & 24.6 & 7.5 & 12.0 \\
\hline CDG method & 26.4 & 7.9 & 13.2 \\
\hline Average heat release & 25.5 & 7.7 & 12.6 \\
\hline Combustion efficiency [\%] & 90 & 71 & 85 \\
\hline \multicolumn{4}{|c|}{ Emission factor $[\mathrm{mg} / \mathrm{g}]$} \\
\hline $\mathrm{CO}_{2}$ & 1654 & 552 & 765 \\
\hline $\mathrm{CO}$ & 36 & 21.6 & 29.6 \\
\hline Soot & 48.8 & 11 & 43.9 \\
\hline $\mathrm{SO}_{2}$ & 184 & 352.6 & 310 \\
\hline NO & 0 & 4.9 & 5.1 \\
\hline $\mathrm{N}_{2} \mathrm{O}$ & 0 & 1.9 & 2.2 \\
\hline HF & 0 & 268.6 & 221.6 \\
\hline $\mathrm{HCN}$ & 0 & 6.9 & 6.7 \\
\hline
\end{tabular}

\section{FROM SMALL-SCALE EXPERIMENTS TO REAL CONFIGURATION MODELLING}

The FPA fire tests carried out on the different ILs led to the production of significant yields of toxic compounds. Of course, this implies a potential concern, depending on quantities involved over the toxic effects in case of a fire in a realistic configuration. Because of the important cost of ILs, it is unrealistic to perform large-scale pool fires, so the only way to evaluate real scale toxicity is dependent on the ability to carry out numerical simulations. 
The starting point of a fire numerical model is in the ability of describing the fire behavior both in terms of power and toxic gases production. Being able to describe the heat release rate of an IL fire depends on the knowledge of the product properties and mainly the mass loss rate and the heat of combustion. As described in our previous paper [23], and mentioned earlier in the present one, those two physical characteristics were measured during the FPA fire tests. These data can be used to build a realistic HRR.

Concerning the toxic gas production rate, the source term was built based on the smoke gas measurements done during the FPA tests coupled with the FTIR spectroscopy system. Induced reduction in visibility was not taken into consideration here due to atypical nature (mostly inorganic) of particulate emissions.

\section{The Numerical Modeling}

The FDS (Fire Dynamic Simulator) CFD (Computational Fluid Dynamics) code was used for toxicity prediction in a realistic geometry. This code was especially developed for fire consequences prediction [24]. As all CFD codes, if the validations available in the literature are crucial, specific validation cases by users are also highly important. This code was evaluated by INERIS on its specific application, including toxic gases dispersion associated with [25] or without a fire scenario [26].

This code is based on a LES (Large Eddy Simulation) turbulence modeling concept that enables to predict with a quite great precision the toxic gas dispersion.

In the present case, the CFD approach was mainly used to give an illustration of the possible toxic impact in case of fire of an $\mathrm{IL}$. While homogeneous approaches can give first evaluation of such toxicity, it is important to evaluate whether or not the energy released by the fire is sufficient for maintaining toxic gases stratification.

\section{Toxicity}

The large variety of gases produced in the IL fire suggests that taking into account their potential cumulative effects as described in ISO $13571[10]$ is actually here a requirement. This standard defines the FEC (Fractional Effective Concentration) relating to concentration-dependent toxic potency of irritant species that are found in fire gases. The concept integrates additive effect of each irritant gas present. A value of FEC higher than 1 is critical towards self evacuation of concerned people, that in such a case are considered incapacitated and therefore need to be rescued. Using this criterion in the numerical modeling generates a clear view of the toxicity area, but it also requires that the numerical model be modified to support the approach.

The FEC concept integration in our modeling work has been based on the assumption that the relative concentrations between the different toxic gases are kept constant. This means more physically that we validate that the proportions between the toxic products generated are not significantly modified by species transport.

In order to illustrate the fire induced toxicity potential concern presented by ILs in case of a fire, a case study comparing same pool fire scenario (same pool size) of two ILs was considered integrating appropriate input data from our experiments. The comparison is based on the FEC distribution in the computed domain. This domain was chosen to have realistic size but small enough to limit the computation time. The domain was then design as a room of $10 \times 10 \mathrm{~m}^{2}$ area and $5 \mathrm{~m}$ height with homogeneous cell size of $0.1 \mathrm{~m}$ in each direction. The fire size that was considered was on-purpose chosen as quite small given that current applications in chemical processing rely on use of very limited quantities of ILs as solvent and/or catalysts. Accordingly, the pool that would result from a leak in that reactor may be assumed actually quite limited in surface. In our calculations, the pool area was fixed to $0.04 \mathrm{~m}^{2}$. This configuration has as its main 
advantage to be close enough to the FPA tests to make the measured values be representative. A standard ventilation system was modeled in this building with a flow rate of 3 times the building volumes each hour.

The methodology used for integrating the FEC calculation routines was identical for all considered liquids. It is here detailed for the PYR $\mathrm{P}_{14}$ TFSI product. First the emission factors of the different products for the PYR PI $_{14}$ TFSI FPA test are taken from Table 2. This table also gives the individual threshold for building the critical FEC value and couples it with the individual concentration.

Table 2. Toxic results for the FPA test with $\mathrm{PYR}_{14}$ TFSI ionic liquid.

\begin{tabular}{lccccccc}
\hline Toxic Product & $\mathrm{CO}_{2}$ & $\mathrm{CO}$ & $\mathrm{SO}_{2}$ & $\mathrm{NO}$ & $\mathrm{N}_{2} \mathrm{O}$ & $\mathrm{HF}$ & $\mathrm{HCN}$ \\
\hline $\begin{array}{l}\text { Emission factor } \\
{[\mathrm{mg} / \mathrm{g}]}\end{array}$ & 765 & 29.6 & 315.4 & 5.1 & 2.2 & 221.6 & 6.7 \\
$\begin{array}{l}\text { Relative proportion } \\
{[\%]}\end{array}$ & 49.6 & 3 & 14.1 & 0.5 & 0.1 & 31.6 & 1 \\
$\begin{array}{l}\text { FEC threshold [ppm] } \\
{[10]}\end{array}$ & - & - & 150 & 250 & - & 500 & - \\
\hline
\end{tabular}

Keeping in mind that the FEC is representing the cumulative effects of the different irritant gas, it consists in the following sum:

$$
X_{F E C}=\frac{\varphi_{H C l}}{F_{H C l}}+\frac{\varphi_{H B r}}{F_{H B r}}+\frac{\varphi_{H F}}{F_{H F}}+\frac{\varphi_{S O_{2}}}{F_{S_{2}}}+\frac{\varphi_{N O_{2}}}{F_{N_{2}}}+\frac{\varphi_{\text {acrolein }}}{F_{\text {acrolein }}}+\frac{\varphi_{\text {formaldehyde }}}{F_{\text {formaldehyde }}}+\sum \frac{\varphi_{\text {irritant } t}}{F_{C_{t}}}
$$

In this formula, $\varphi$ represents the local concentration of the given gaseous substance while $F$ give the threshold as indicated in above table. In the present case, considering that NO can be assimilated to $\mathrm{NO}_{2}$, formula can be reduced to:

$$
X_{\mathrm{FEC}}=\frac{\varphi_{\mathrm{HF}}}{F_{\mathrm{HF}}}+\frac{\varphi_{\mathrm{SO}_{2}}}{F_{\mathrm{SO}_{2}}}+\frac{\varphi_{\mathrm{NO}_{2}}}{F_{\mathrm{NO}_{2}}}
$$

It is obvious that the contribution of $\mathrm{NO}_{2}$ in the present case is very limited. As described previously, this value must stay under 1 to ensure safety conditions for people during the evacuation phase.

\section{Numerical Results}

Before going any further in the toxicity evaluation, it is important to evaluate the thermal consequences of the fire. Among the considered product, the lowest HRR is $266 \mathrm{~kW} / \mathrm{m}^{2}$, generated by the PYR 14 TFSI, the highest one is $1416 \mathrm{~kW} / \mathrm{m}^{2}$, the variety of total power generated by the small fire size stay limited as presented in Fig. 2. 


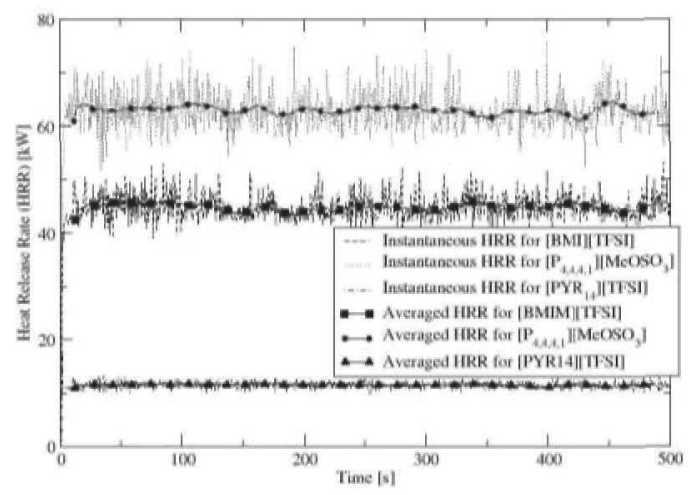

Figure 2. Heat Release Rate developed for the different products.

Those values must clearly be kept in mind in the toxicity results analysis because of the direct linked with the potential stratification. This analysis is presented on Fig. 3 to Fig. 5 for the different considered ILs through the FEC distribution in the central plane of the room. Those pictures correspond to a steady state reached after about two minutes. The legend is identical between the different pictures.

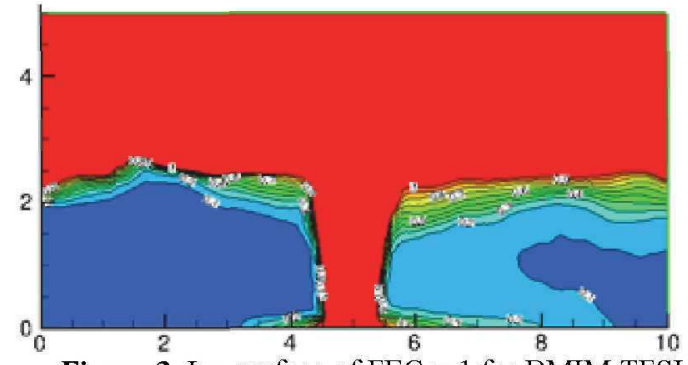

Figure 3. Iso-surface of FEC $=1$ for BMIM TFSI

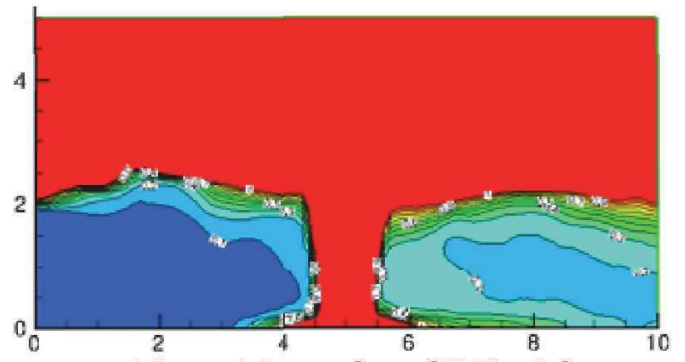

Figure 4. Iso-surface of $\mathrm{FEC}=1$ for $\left[\mathrm{P}_{4,4,4,1}\right]\left[\mathrm{MeOSO}_{3}\right]$

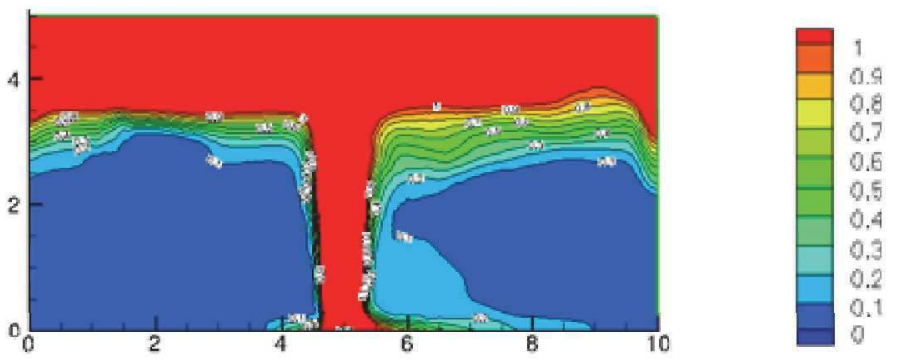

Figure 5. Iso-surface of $\mathrm{FEC}=1$ for $\mathrm{PYR}_{14} \mathrm{TFSI}$.

These values show that, for such a very small fire, the toxicity remains low enough in the lower part of the building during people evacuation. It must be kept in mind, however, that this situation corresponds to a very small fire. The associated temperature for that case stay limited as shown on Fig. 6. 


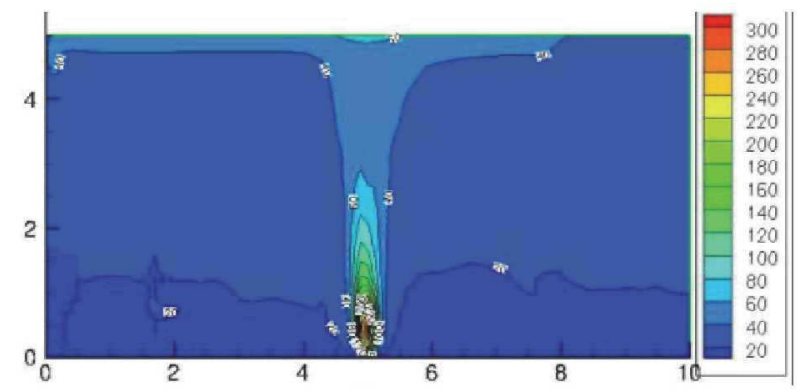

Figure 6. Temperature distribution in the central plane of the room after having reached the steady state.

Despite the low level of temperature reached in the domain, a certain thermal stratification is observed in the building. This, of course, favors the toxic stratification observed in previous pictures.

The first simulations correspond to a very small fire; the case of a larger fire, $1 \mathrm{~m}^{2}$, with the $\left[\mathrm{P}_{4,4,4,1}\right]\left[\mathrm{MeOSO}_{3}\right]$ product generates a different conclusion as shown in Fig. 7 . The blue rectangle on this picture corresponds to one of the obstacle.
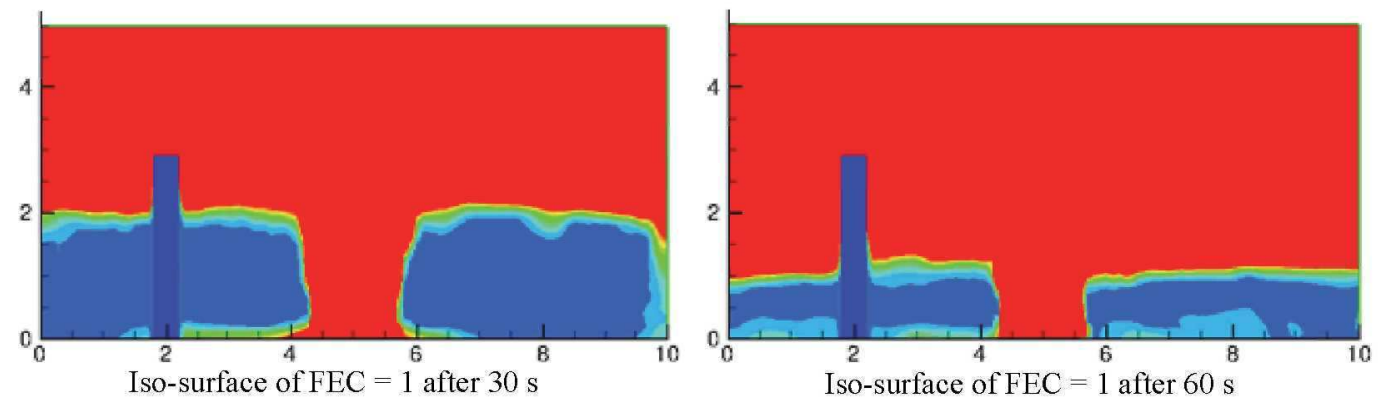

Figure 7. Time evolution of the $\mathrm{FEC}=1$ iso-surface in case of $\left[\mathrm{P}_{4,4,4,1}\right]\left[\mathrm{MeOSO}_{3}\right]$ product $1 \mathrm{~m}^{2}$ pool fire.

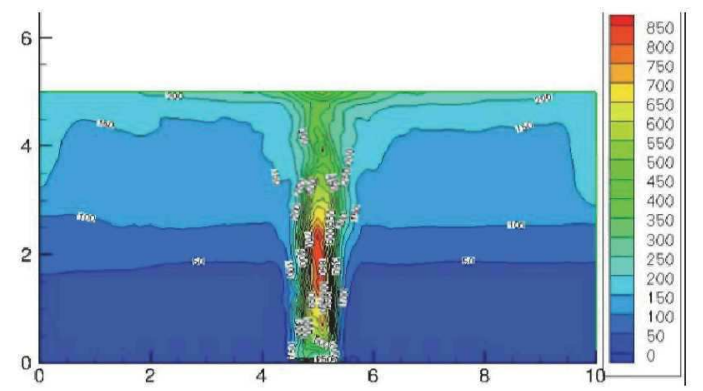

Figure 8. Temperature distribution in the central plane of the room $60 \mathrm{~s}$ after the fire ignition.

As shown in these pictures, the FEC becomes larger than 1 in the lower part of the room after only 1 minute, meaning that evacuation will become highly dangerous for people located inside the enclosure. While this duration can appear highly short, the infinitely quick fire growth considered in this simplified case lets indicates that some additional seconds should be offered to people for the evacuation. 
On top of this toxicity effect, the temperature increase inside the building is more important because of the higher heat release rate due to the larger size of the fire. The temperature distribution is shown in Fig. 8.

For that size of fire, temperatures quickly increase and can also generate some thermal effects on people before or during evacuation.

\section{CONCLUSION}

ILs are more and more used in different industrial applications because of some highly specific properties that make them highly tunable according to desired functionalities. The specific atomic composition of many ILs raises concerns about the consequences in case of fire, particularly with regards to toxicity. Estimating toxic consequences in case of fire, requires being able to predict the smoke composition. Because of the high complexity of the ILs molecules, predicting this composition imposes an experimental approach. As detailed in this paper, this was previously done using the FPA coupled with an FTIR spectrometer.

The approach presented in this paper consists in coupling these small-scale FPA measurements with a CFD approach to predict toxic consequences in case of an IL fire in a realistic industrial configuration. Because of the large variety of toxic compounds, their relative impact on the total toxic effects must be considered using fractional effective concentration (FEC) and/or dose (FED) approaches (as developed in ISO13571 for incapacitation) or other adverse effects of fire toxic components. Such an approach was developed thanks to the FDS fire code that enables modeling of thermal consequences of a fire but also the toxic gas dispersion inside an enclosed.

While the fire size considered in this paper is small, $0.04 \mathrm{~m}^{2}$, simulations for IL fires shows that the toxicity inside the building quickly increase. In case of a larger fire, the toxic gas concentration near the ground quickly becomes high enough, by having a FEC larger than 1, which means that toxic effects on people must be considered.

Of course, the results shown in this paper were obtained based on a first quite simplified approach to be improved. This, however clearly shows that the toxic consequences in case of IL fires cannot be neglected and keep highly scenario dependent.

\section{REFERENCES}

1. Sakaebe, H., Matsumoto, H., and Tatsumi, K. "Application of Room Temperature Ionic Liquids to Li Batteries," Electrochimica Acta 53 (3): 1048-1054 (2007).

2. Zhu, S., Wu, Y., Chen, Q., Yu, Z., Wang, C., Jin, S., Ding, Y., and Wu, G. "Dissolution of Cellulose with Ionic Liquids and Its Application: a Minireview," Green Chemistry 8: 325-327 (2006).

3. Abbott, A.P., Frisch, G., Hartley, J., and Ryder, K.S., "Processing of Metals and Metal Oxides Using Ionic Liquids," Green Chemistry 13: 471-481 (2011).

4. Predel, T., "Ionic Liquids as Operating Fluids in High Pressure Applications," Chemical Engineering \& Technology 30: 1475-1480 (2007).

5. Lu, J., Yan, F., and Texter, J., "Advanced Applications of Ionic Liquids in Polymer Science," Progress in Polymer Science 34(5): 431-448 (2009).

6. Ngo, H.L., LeCompte, K., Hargens, L., and McEwen A.B., "Thermal Properties of Imidazolium Ionic Liquids," Thermochimica Acta 357-358: 97-102 (2000).

7. Bonhôte, P., Dias, A.P., Papageorgiou, N., Kalyanasundaram, K., and Grätzel, M., "Hydrophobic, Highly Conductive Ambient-Temperature Molten Salts", Inorganic Chemistry 35: 1168-1178 (2011).

8. McEwen, A.B., Ngo, H.L., LeCompte, K., and Goldman, J.L., "Electrochemical Properties of Imidazolium Salt Electrolytes for Electrochemical Capacitor Applications," Journal of the Electrochemical Society 146: 1687-1695 (1999). 
9. Schneider, S., Hawkins, T., Rosander, M., Vaghjiani, G., Chambreau, S., and Drake, G., "Tonic Liquids as Hypergolic Fuels," Energy Fuels 22 (4): 2871-2872 (2008).

10. ISO 13571:2012 Life-threatening Components of Fire - Guidelines for the Estimation of Time Available for Escape Using Fire Data.

11. Smiglak, M., Reichert, W.M., Holbrey, J.D., Wilkes, J.S., Sun, L., Thrasher, J.S., Kirichenko, K., Singh, S., Katritzky, A.R., and Rogers, R.D., "Combustible Ionic Liquids by Design: Is Laboratory Safety Another Ionic Liquid Myth?," Chemical Communications 24: 2554-2556 (2006).

12. Schaller, U., Keicher, T., Weiser, V., Krause, H., and Schlechtriem, S., "Synthesis, Characterization and Combustion of Triazolium Based Salts," Proceedings of the Insensitive Munitions and Energetic Materials Technology Symposium, October 11-14, 2010, Munich, Germany.

13. Shamshina, J.L., Smiglak, M., Drab, D.M., Parker, T.G., Dykes, Jr H.W.H., Di Salvo, R., Reich, A.J., and Rogers, R.D., "Catalytic Ignition of Ionic Liquids for Propellant Applications," Chemical Communications 46: 8965-8967 (2010).

14. Joo, Y.H., Gao, H., Zhang, Y., and Shreeve, J.M., "Inorganic or Organic Azide-Containing Hypergolic Ionic Liquids," Inorganic Chemistry 49: 3282-3288 (2010).

15. Zhang, Y., Gao, H., Guo, Y., Joo, Y.H., and Shreeve, J.M., "Hypergolic Dimethylhydrazinium Ionic Liquids," Chemistry - A European Journal 16: 3114-3120 (2010).

16. He, L., Tao, G.H., Parrish, D.A., and Shreeve, J.M., "Nitrocyanamide-Based Ionic Liquids and Their Potential Applications as Hypergolic Fuels," Chemistry 16: 5736-5743 (2010).

17. Gao, H., Joo, Y.H., Twamley, B., Zhou, Z., and Shreeve, J.M., "Hypergolic Ionic Liquids with the 2,2Dialkyltriazanium Cation," Angewandte Chemie International Edition 48: 2792-2795 (2009).

18. Liaw, H.J., Chen, C.C, Chen, Y.C., Chen, J.R., Huanga, S.K., and Liuc, S.N., "Relationship between Flash Point of Ionic Liquids and Their Thermal Decomposition," Green Chemistry 14: 2001-2008 (2012).

19. Diallo, A.O., Morgan, A.B., Len, C., and Marlair, G., "Revisiting Physico-Chemical Hazards of Ionic Liquids," Separation and Purification Technology 97: 228-234 (2012).

20. Brohez, S., Marlair, G., and Delvosalle, C., "Fire Calorimetry Relying on the Use of the Fire Propagation Apparatus. Part I: Early Learning from Use in Europe," Fire and Materials 30 (2): 131-149 (2006).

21. Brohez, S., Marlair, G., and Delvosalle, C., "Fire Calorimetry Relying on the Use of the Fire Propagation Apparatus. Part II: Burning Characteristics of Selected Chemical Substances Under Fuel Rich Conditions," Fire and Materials 30 (1): 35-50 (2006).

22. Ribière, P., Grugeon, S., Morcrette, M., Boyanov, S., Laruellea, S., and Marlair, G., "Investigation on the Fire-Induced Hazards of Li-ion Battery Cells by Fire Calorimetry," Energy \& Environmental Science 5: 5271-5280 (2012).

23. Diallo, A.O., Morgan, A.B., Len, C., and Marlair, G., "An Innovative Experimental Approach Aiming to Understand and Quantify the Actual Fire Hazards of Ionic Liquids," Energy \& Environmental Science, 6: 699-710 (2013).

24. McGrattan, K., Klein, B., Hostikka, S., and Floyd, J., Fire Dynamics Simulator (Version 5) User's guide, NIST Special publication 1019-5 (2008).

25. Truchot, B., Boehm, M., and Waylem, F., "Numerical Analysis of Smoke Layer Stability," Proceedings of 13th International Symposium on Aerodynamics and Ventilation of Vehicle Tunnels New Brunswick, New Jersey, USA: 13-15 May 2009.

26. Truchot, B., Fournier, L., and Waymel, F., "Are the Tunnel Ventilation Systems Adapted for the Different Risk Situations?," Int. Symposium on Tunnel Safety and Security, Frankfurt, 2010. 